\title{
De emigrado a rebelde: José Canterac, un militar indeseable en busca de la identidad perdida
}

\begin{abstract}
RESUMEN
José de Canterac, hijo de emigrados contrarrevolucionarios franceses, llegó a ser un oficial modelo de los reales ejércitos de Fernando VII. En 1821 formó parte del grupo de altos oficiales que obligaron al virrey a renunciar, en el primer golpe de estado de la historia del Perú. Los ańos siguientes tampoco fueron favorables a una recuperación histórica de la figura de Canterac, pues firmó las capitulaciones de Ayacucho en nombre de España. Canterac regresó a Francia en 1825 e intentó acercarse a Fernando VII. En esta biografía los informes y cartas de diversas fuentes serán otras tantas escrituras olvidadas gracias a las que la presente investigación quiere participar en la construcción de una historia renovada de las independencias, por encima de las limitaciones de las historias nacionales.
\end{abstract}

Palabras Clave: Independencia del Perú; Canterac; Revolución francesa; Ayacucho; historia militar.

\section{From emigrant to rebel: José Canterac, an undesirable soldier in search of a lost identity}

\begin{abstract}
Son of French counterrevolutionary emigrants, Canterac came to be a model officer of the Royal army of Fernando VII. In 1821 he was part of the group of senior officers who forced the viceroy to renounce, in the first coup in the history of Peru; he signed the capitulations of Ayacucho, with whom Spain lost continental America. Canterac returned to France in 1825 and tried to approach Fernando VII. In this biography the reports and letters from various sources will be so many forgotten writings thanks to which the present research wants to take part in the construction of a renewed history of independence, beyond the limitations of national histories.
\end{abstract}

KeYwords: Independence of Peru; Canterac; French Revolution; Ayacucho; military history. 
I nteresarse por José Canterac es volver a unas fuentes a menudo descuidadas pues la historiografía latinoamericana ha enfocado la construcción de la historia de la independencia en base a escritos patrióticos y privilegiando la afirmación nacional con fines educativos. Aquí se intenta completar ese acercamiento acudiendo a otra versión de los hechos, igualmente trunca, a partir del dossier del Archivo Militar de Segovia ${ }^{1}$ y documentos comunicados por Ascensión Martínez Riaza cuyo punto de vista es compartido sobre la confusión de nombres existente en la versión popular peruana de la independencia que condena a Canterac como represor encarnizado como otros oficiales españoles como Carratalá y Ricafort.

Canterac fue uno de los generales partícipes del motín de Aznapuquio, considerado como el primer golpe militar en el Perú, pues fue derrocado el virrey Pezuela y ascendió La Serna, en enero de 1821. La Independencia del Perú fue proclamada en julio de este año y Lima evacuada por las autoridades de la Corona. La guerra iniciada en los territorios integrantes del virreinato desde 1816 perduró como lucha fratricida hasta 1824. El 9 de diciembre de 1824, apresado el virrey por las tropas patriotas, en el lugar de La Serna, Canterac firmó las capitulaciones de Ayacucho, lo que le valió ser retratado en el cuadro de Daniel Hernández, a los cien años de la victoria patriota $^{2}$. La documentación del Archivo Militar permite además completar la información sobre el destino de Canterac después de desembarcar al puerto de Burdeos en junio de 1825 .

\section{Una tradición militar y familiar}

Hijo del capitán de los reales cuerpos de artillería Alexandre Pierre de Canterac d'Ornezan ${ }^{3}$, César

1 Las referencias remiten a los legajos C. 1004-0 y a la Caja 25-Exp. 3, carpetas 1, 2, 3, 4 microfilmadas. El expediente consultado en Segovia no proporciona información sobre los años 1816-1825, desde la partida de España hasta el regreso después de la batalla de Ayacucho.

2 Una noticia biográfica se debe a Martín-Lanuza Martínez (2012, 167-168) y me fue facilitada por el historiador francés Jean-René Aymes, especialista de la guerra de independencia espańola.

3 Hallé el certificado de bautismo de Canterac en los archivos parroquiales digitalizados del departamento de Lot-et-Garonne. Ese documento permite conocer el primer nombre de Canterac "César", hijo de "Alexandre», o sea que fue predestinado a la vida militar y formaba
José de Canterac nació el 29 de julio de 1786 en Casteljaloux, un pueblecito ubicado en el suroeste de Francia ${ }^{4}$. Siguió los pasos de su padre, emigrado contrarrevolucionario radicado en Castilla. Los bienes de la familia fueron embargados y vendidos en pública subasta el 23 de diciembre de 1792. El inventario archivado en Agen ${ }^{5}$ da cuenta no sólo de sillas, sillones y todo tipo de muebles, prendas de vestir, incluyendo una bañera, un "muy hermoso billar casi nuevo» en una habitación separada, unos carruajes y una librería con varios centenares de libros repartidos entre los cinco pisos de la casa, treinta y nueve volúmenes de la Enciclopedia, varios diccionarios (uno de italiano) así como colecciones de un diario titulado El amigo del rey ("L'ami du roy»).

Alejandro de Canterac obtuvo el ingreso de su hijo de quince años a las guardias valonas, un cuerpo de infantería española mandado por oficiales francófonos. Entre dos nacionalidades y dos tradiciones lingüísticas, el cadete tuvo que adaptarse constantemente a sus interlocutores, transar con la identidad para integrarse y a la vez siguió discretamente fiel a las raíces francesas, un vaivén que se observa en las variaciones a la hora de firmar. En 1803, al solicitar el ingreso a un cuerpo de artilleros se presenta como Josef Cesáreo De Canterac D’Ornezan. Después de cuatro años, en 1807, él mismo suprime la primera partícula (de) pero conserva la segunda, con la tilde tan propia del francés: Josef Canterac D’Ornezan, en una carta a la que desde Madrid se le contesta catalanizando el apellido en "Canterach». Para recuperar bienes requisados en tiempos de la Revolución, el padre de José Canterac se dirige al general que lo manda para

parte de la nobleza rural de Guiena. El padre de José Cantérac, Pierre de Cantérac d'Andiran, jefe de batallón de artillería, nacido en 1746, fue dado de baja en 1791. Con motivo del centenario de la batalla de Ayacucho en 1924, el comandante Labouche publicó en la Revue de l’Agenais una primera biografía de Canterac (págs. 444-451)

4 Según consta en el registro de casamiento, Alexandre Pierre de Cantérac d'Ornezan capitán de los reales cuerpos de artillería es casado el 8 de junio de 1785 en Casteljaloux con Dońa Julie Marie Dorlie hija de de Jacques Gratien Benou y Marie Caillau. Se calcula la hacienda de Alexandre Canterac d'Andiran en 40 000, no hay indicación sobre la dote de la novia.

5 La lectura del legajo 1Q109 «Bien des émigrés» es reveladora; da la impresión de un ensańamiento contra padres y abuelos, a lo que se suma el hecho de que el notario firmante del casamiento y el escribano encargado del embargo llevan el mismo apellido (Lartigue). Incluye el decreto del 28 de marzo de 1793 contra los emigrados "civilmente muertos y cuyos bienes pertenecen a la República». Se agrega que sólo se salvan de la condena a muerte los hijos de emigrados menores de catorce ańos e inermes. 
que autorice una estadía de varios meses en Francia. El pedido es urgente y dramáticamente revelador de la situación de apuros económicos (29 de agosto de 1807); además, la carta escrita desde Barcelona cuando José está en Palma comprueba la dependencia de padre e hija:

él tiene una urgente necesidad de acorrer $[s i c]$ a Francia para presentarse como acreedor mío y reclamar con esa calidad sobre la Succesión [sic] del Conde De Saluces que se abrió el 28 del mes de julio próximo pasado, por haber llegado en ese época de heredero de esa casa a ser mayor de edad; reclamar; digo, una deuda de 80.000 Ns que me pertenecen como prestados, y no han sido denunciados a la nación, que son el único resto de la fortuna mía considerable que perdí; y aun he perdido el derecho de formar pretensión sobre este mismo pequeño resto, pues soy reputado muerto civilmente [subrayado por el autor de la carta] y quedo privado en calidad de emigrado de todo fuero juicial [sic] pero la misma ley, que me mata, y excluye todo recurso mío, ha conservado a mis hijos, el Derecho de reclamar ese efecto, por ser hipoteca de una porción de la Dote de su madre, que yo había alienado, hipotecando mis bienes, para representar su valor. Digo ser urgente que se presente mi hijo porque siendo crecidísimas las deudas de la casa Desaluces, que era tan empeñado, como pudiente, es probable que la sucesión [...] quede en totalidad absorta por los acreedores VS no dejara de perdonar al afectuoso y bien fundado cuidado de mi hijo y el mío, que no tenemos otro recurso para dar una dote a mi desdichada hija [...].

Pese a la autorización otorgada, la situación familiar siguió igual de mala. El expediente del archivo militar no incluye ninguna información sobre algún resultado favorable para los Canterac. En el archivo del departamento del Lot-et-Garonne (Legajo 1Q109), figura una carta del 13 de diciembre de 1808 con una petición al inspector de impuestos sobre la situación de los activos del emigrado Dandiran Canterac, con la finalidad de una indemnización; la contestación (que no está en el legajo) fue enviada al Director de los Registros el 20 de mayo de 1809.

A partir de 1808, el joven emigrado participó en la guerra de Independencia de España en la caballería castellana. Herido en el sitio de Gerona, fue ascendido al grado de teniente coronel. El teniente general
Enrique O' Donnell atestiguó en una carta fechada del 1 de abril de 1810 la «vizarría» en la acción de Vic y más adelante en las trincheras de Tarragona y otras batallas que le valieron medallas de honor. Después de combatir con las tropas napoleónicas en distintos frentes (derrota de Sagunto, 1811; victoria de Sevilla y Pamplona, 1813), ascendido a coronel, estuvo en la batalla contra los franceses en Toulouse (1814), junto al inglés Wellington. En julio de 1814, derrotado Napoleón y restablecida la monarquía de en Francia, Canterac solicitó un permiso para ir a Burdeos. Sobre esa presunta segundo visita no se da más información en el legajo "Canterac».

Considerándose completamente integrado a los ejércitos españoles, Canterac reclamó otro ascenso en 1815 , a los 29 años. Esa solicitud fue tachada como muestra de excesiva ambición por el inspector de Caballería quien censuró ante el rey Fernando VII «la notable falta de subordinación en que ha incurrido $[. .$.$] contemplando en este sujeto el verdadero$ carácter de un francés emigrado y de muy cortos servicios excesivamente premiados por SM y siempre descontento» ${ }^{6}$. Pero José Canterac fue recompensado como caballero de la Orden de San Fernando. Ante el pedido de ir a América, desde el ministerio de Guerra, otra carta se opuso a esa petición de Canterac (6 de agosto de 1816): «puede ser peligroso al servicio de SM, pues estando en la península su amor propio no le permitió sujetar su ambición en los justos y precisos límites que exigen la prudente moderación». No obstante llegó la autorización y Canterac pidió que fuera asignada a su padre y hermana parte del sueldo que le correspondía desde Valladolid (22 de noviembre de 1816), una información reveladora de las necesidades familiares y solidaridad del oficial con los suyos. Había de llevar al Perú una división de tres mil hombres ${ }^{7}$ pasando por Panamá. En Porto Belo, le llegó una contraorden para que fuera a reunirse con la expedición de Morillo en el litoral venezolano.

6 Carta del inspector de Caballerías, Ballesteros, citada por Eugenio de Santos Rodrigo en "Canterac: apuntes biográficos ", Revista de Historia Militar, $\mathrm{n}^{\circ}$ 39, Madrid, 1975, págs.76-98.

7 Julio Albi en Banderas olvidadas. El ejército realista en América (Madrid, 1990, Cultura Hispánico, 189) da la composición de la división bajo las órdenes de Canterac: dos batallones de Navarra, el II batallón de Burgos, un escuadrón de lanzas, otro de cazadores a caballo y una compañía de artilleros. 


\section{La etapa venezolana. Mayo-setiembre de 1817}

La división bajo las órdenes de Canterac debía reconquistar la isla de Margarita ganada por Morillo en 1815 y recuperada por Bolívar al año siguiente; las tropas peninsulares fueron derrotadas en los combates en julio y agosto de 1817; la Esparta venezolana quedó en manos de los patriotas. Canterac permaneció de mayo a setiembre de 1817 en la Costa Firme; la actuación del francés se devela en las cartas que envió a Morillo ${ }^{8}$. Canterac se dirige a Morillo mezclando respeto, familiaridad y a la vez sincerándose, un tono que, sin duda, se explica por la camaradería militar y el desparpajo de quien sigue siendo un extraño en momentos de escribir un correo. La frase de despedida varía entre la cordialidad: "siempre su affmo y pa siempre amigo y servidor que VBM» (f. 113) y la sequedad de un simple "adiós» (f. 112). Algunas torpezas lingüísticas están diseminadas en las cartas como otros tantos indicios de que Canterac no tiene a un secretario que le corrija "la agua», "Echavarria que me parece un gran collon» (f. 112). Sugiere operativos y recibe información de un espía francés sobre la situación en la isla de Trinidad.

Pero este epistolario se distingue sobre todo como pliego de reclamos. Los soldados están pasando penurias, muchos, incluidos los oficiales recién llegados de España padecen disentería, Canterac protesta: «es inútil nos mantengamos en la miseria y privaciones de toda especies [sic] que aquí experimentamos» (ff. 114-115). Anuncia que recurrirá a los prisioneros para catar el agua de los pozos, a falta de vino. Espera recibir carne para cambiar del pescado cogido in situ; confiesa: «no puede escribir más largo impedido de un horrible dolor de caveza [sic] que he pillado aguantando sol y agua para hacer la pesca con el chinchorro (f. 113). Desde Cumana el 26 de agosto de 1817, observa que las dos mil raciones que les corresponden siempre llegan en cantidad inferior; los soldados españoles no han recibido pantalones, chaquetas, zapatos ni camisas desde hace meses, los uniformes están terrosos por falta de jabón y no se les ha pagado, por lo que presenta las cuentas detalladas de todo lo que se les debe. Pide encaminarse al Perú con la división a sus órdenes, tal

876 folios del año 1817 han sido digitalizados por la Real Academia de Historia. Además se puede consultar el Catálogo de la colección de Pablo Morillo editado por Remedios Contreras (t. II, Madrid, RAH, 1989) y cual fue previsto en momentos de la salida de Cádiz. Después de semanas de inútiles protestas, enfrentando las negativas de Morillo, el general de origen francés es autorizado a partir rumbo al Perú a bordo de la goleta La Patriota, solo acompañado por un edecán. Pablo Morillo informa al ministro de Guerra sobre las quejas de Canterac, lo cual refuerza la mala fama de éste en Madrid.

\section{Epistolario íntimo 1818-18239}

A diferencia de la etapa de unos meses en Venezuela, el francés permaneció seis años, entre 1818 y 1824, en el vastísimo territorio peruano, encabezando numerosas batallas hasta perder en Ayacucho. Después de veinticuatro años fuera de Francia, desembarcó en el puerto de Burdeos y a los pocos días publicó una carta en un diario de esta ciudad el 21 de julio de 1825 (Memorial Bordelais $\mathrm{n}^{\circ}$ 4650) para justificar su actuación y responsabilizar al secesionista Olańeta del fracaso.

Una primera parte de las cartas dirigidas al intendente de la provincia de Arequipa fueron escritas desde Oruro y Tupiza. Canterac fue enviado a los confines del virreinato, cerca de los salares de Uyuni y de la ciudad de Tarija por casi dos años. Aunque acantonado a unas cincuenta leguas de Potosí, nunca menciona el centro minero. Tan alejado de Lima como de Buenos Aires, no obstante, tiene una visión de la situación continental, desde ese frente en que la guerra es un conflicto de baja intensidad, unas tierras limítrofes de las Provincias del Río de la Plata, del Virreinato del Perú y de la Capitanía General de Chile. En los primeros meses de esa estadía en el altiplano altoperuano, Canterac trata de vislumbrar el porvenir político pues, pese al alejamiento geográfico, recibe noticias de Chile, primero alentadoras y repentinamente abrumadoras por no llegar la escuadra imprescindible anunciada de Cádiz. Desde entonces, el Pacífico queda en manos de los insurgentes, como los denomina Canterac, o sea los patriotas. El general francés relata su deseo de actuar, apunta los errores en la estrategia española y critica las vacilaciones del poder en Lima, siendo el virrey Pezuela muy cercano a Osorio, incluso por lazos familiares. Canterac

9 Cristina Mazzeo me facilitó el acceso al epistolario que obtuvo de los descendientes de la familia Lavalle (véase la bibliografía). 
sueña con lanzar una ofensiva en lugar de estar obligado a permanecer en la defensiva. Observa cómo el caos se apodera de aquellos territorios que formaron el Virreinato del Río de la Plata. A su parecer, cada caudillo impone sus leyes y la apertura del comercio internacional ha empobrecido a los lugareños. Otro motivo de desacuerdo con Pezuela es que permite en Lima el comercio exterior, en condiciones provechosas a extranjeros como el capitán Camille de Roquefeuil enviado por un armador bordelés para abrir nuevas rutas comerciales, trocando productos entre Europa, América y China. En cambio, Canterac es menos prolijo sobre los operativos de "pacificación» que lleva a cabo en Salta. Parece contento por los primeros trofeos que consigue; dispone de ochocientos caballos y más de mil sillas, según refiere a Juan Bautista Lavalle. En el Alto Perú, se dedica a formar una caballería, instruyendo hombres que nunca se destinaron a la guerra. Cumple ese cometido y lleno de orgullo, registra la formación de los escuadrones ante el general en jefe Ramírez.

En esas cartas íntimas curiosamente Canterac resulta muy reservado. Apenas evoca una enfermedad de la que se va restableciendo gracias a la altura en 1818. En la segunda parte del epistolario, aquella que corresponde a los años 1821-1824, al contrario, reincide en el tema de su salud. Con frecuencia, en las confidencias al amigo arequipeño alude a su debilidad física. Alguna vez precisa que si las tercianas y fluxiones le incomodan, no se desviará del propósito por el que arribó al Perú, o sea liberar el virreinato de sus «destructores y opresores» para devolverlo a España, a la que define como "la Madre Patria», una fórmula que asevera la integración del general de origen francés al mundo hispánico.

En Lima, la independencia fue proclamada en julio de 1821. Desde entonces los «nacionales», o sea los realistas se han replegado en la sierra, convirtiendo la ciudad del Cusco en la capital del virreinato. Durante tres años, los dos ejércitos se acuartelan esperando refuerzos y llevando ataques que no determinan un cambio favorable a unos o a otros. Se trata de una guerra de desgaste, una situación indefinida que en parte se explica por la inestabilidad de la monarquía en la península, después que Fernando VII se vio obligado a aceptar la constitución liberal por el éxito del pronunciamiento de Rafael de Riego. Canterac refiere que en el bando nacional cunde el rumor de que San Martín ha muerto (febrero de 1822) y el general realista espera la llegada de la armada española. Ascendido a brigadier, vence la División del Sur en abril del mismo año y describe el espectáculo de los oficiales patriotas heridos: "Gamarra lleva una cuchillada en la cabeza que se le ven los sesos, Eléspuru y Bermudes el brazo roto: muchos jefes muertos» (17 de abril de 1822, carta 54). El triunfalismo define ese momento que parece «fijar la suerte del Perú». En febrero de 1823 Canterac nuevamente resulta vencedor en Torata y Moquegua y según escribe, anhela que llegue una "paz octaviana». Ascendido a teniente general, llega a ocupar nuevamente Lima en junio de 1824 y cree la victoria aún posible; la considera solo retrasada por «las desavenencias con Olañeta [...] más perjudiciales que lo que puedan hacer los más malos caudillos y así es que si cesan [...] pronto concluirá la guerra del Perú» (carta a Juan Bautista La Balle [sic], Huancayo, 15 de marzo de 1824). Olañeta tachaba a La Serna y a los demás generales de su entorno de liberales, mientras reivindicaba un apoyo constante a Fernando VII y al régimen absolutista restablecido después de la ejecución de Rafael del Riego ${ }^{10}$.

Ese epistolario íntimo deja un sentimiento de frustración; pero lo implícito y el silenciamiento se explican por los riesgos de ver embargada la correspondencia. Algunos mensajes parecen repeticiones y formulismos que sólo sabría descifrar el destinatario. De hecho los patriotas constantemente infiltran y espían el bando realista. La reserva en las cartas intercambiadas contrasta con las informaciones muy precisas que encontramos en los resúmenes mensuales de 1818 desde el Alto Perú, y luego con los partes sobre las campańas sucesivas a partir de 1821.

\section{Los partes oficiales de junio a noviembre de 1818}

Los «resúmenes históricos» fueron escritos desde distintos lugares del Alto Perú, hoy colindantes con Argentina y Chile ${ }^{11}$. Allí Canterac refiere las pecu-

10 Véase Ascensión Martínez Riaza, «Todos eran realistas. Liberalismo y absolutismo en el gobierno del virreinato del Perú», Izaskun Álvarez Cuartero y Julio Sánchez Gómez, Visiones y revisiones de la independencia americana. Realismolpensamiento conservador..., Salamanca, ed. Universidad de Salamanca, 2014, 121-143. La «Década ominosa» se prolongó hasta la muerte de Fernando VII en 1833.

11 CDIP, La acción patriótica del Pueblo en la Emancipación. Guerrillas y montoneras, t. V, v. 1, ed. Ella Dunbar Temple, Lima, 1971, 17-25. 
liaridades locales a sus superiores alejados del campo de batalla. Cita una serie de provincialismos con una sensibilidad lingüística que no se transparentaba en las cartas desde Venezuela. Desde el cuartel general de Tupiza en junio de 1818, describe la topografía que le asombra: las vastas llanuras "llamadas pampas», un territorio "pedregoso y árido", " los arbustos llenos de pinchos y abrojos» adaptados al clima inhóspito, las dificultades respiratorias que atribuye a "gases que se desprenden de [la] superficie llamada [sic] en el país soroche». Luego retrata a los soldados bajo sus órdenes, aquellos «a los que llaman de Jujuy abajo por apodo cuicos [...] son hombres en lo general pequeños, robustos sobrios, fuertes, callados, humildes y valientes»; siempre van acompañados con su «moza (llamada chola)»: «en el mismo acto de quitárseles no queda uno»; por lo que hace falta «el tolerantismo de parte de los Gefes».

Además Canterac expone su preferencia por la quinta antes que la leva propicia a la deserción en masa que suele observarse cuando llegan los tiempos de cosechar. El ejército nacional se compone sobre todo de soldados nacidos en tierras americanas, situación que no dejará de reforzarse con el paso del tiempo y por el distanciamiento militar de España enfrentada a las luchas internas entre liberales y conservadores desde 1820 .

Los enemigos que son los gauchos se ven comparados con «cosacos» acostumbrados a embestir al enemigo, también con los guerrilleros que participaron en la guerra de independencia de la propia España. Sortean el cuerpo a cuerpo y anteponen las emboscadas para acosar a las tropas realistas. La situación que viviera Canterac en la península antes de 1816, se invierte en tierras americanas como él mismo lo comprueba recurriendo a un colectivo "nosotros» que revela el apego y la identificación completa con España a la que sirve contra los «rebeldes» y por «la justa causa de nuestro amado Soberano» (23).

Canterac observa cómo las armas de los enemigos son heteróclitas: desde fusiles ingleses o rifles de mucho alcance y sables esgrimidos con destreza, también lazos y hondas que le inspiran admiración por ser empleados desde muy lejos y con increíble puntería para inmovilizar a hombres y caballos. Sucede que las tropas porteńas incendian la pampa; los insurgentes también lanzan peñascos desde lo alto de los cerros, lo cual obliga a que los soldados transiten por las que- bradas más angostas. Para los nacionales, el objetivo es apoderarse de las reses (Canterac apunta la captura de 1000 cabezas de ganado vacuno en agosto de 1818 y 2000 en setiembre del mismo año) y «exterminar» a los «revolucionarios». En Chuquisaca, el 8 de agosto, las cabezas de los jefes han de permanecer expuestas en la horca "para público escarmiento" (29). El tono de los escritos de Canterac es contradictorio, entre violencia de la represión y amabilidad, a imagen y semejanza de un conflicto que es a la vez una guerra colonial y una guerra civil, un conflicto en el que el francés encuentra a oficiales que conoció en España o bien cuya formación comparte. San Martín, quien combatió en España las tropas napoleónicas, es citado por la formación militar que ha llegado a inculcar a los gauchos, como quiere hacerlo el propio Canterac, convirtiendo en veteranos a los conscriptos levados y a los reclutas voluntarios. Un croquis hecho por Canterac ilustra a la vez el frente al que fue destinado al llegar de Venezuela, momento que corresponde a la internacionalización del conflicto, y enseña las posiciones hacia las que se desplaza en los años 1821-1824, desde el derrocamiento de Pezuela hasta la victoria/derrota de Ayacucho, dos acontecimientos en los que Canterac desempeñó un rol de primer plano a expensas de los intereses de la metrópoli que representaba.

\section{1-1824: desde el motín de Aznapuquio hasta la batalla de Ayacucho}

Julio Albi, especialista del ejército español en América, define a José Canterac como el «más notable [entre los oficiales] que llegaron con los cuerpos peninsulares» (Albi, 2009, 125) pues permitió «un salto cualitativo en la evolución de las fuerzas realistas» $\mathrm{y}$ «lo que no era frecuente, Canterac militó sucesivamente en infantería, artillería y caballería para acabar en el estado mayor, prueba de que se le tenía por oficial excepcionalmente capaz», comenta Albi (126). La tropa aumentó de 5.823 efectivos a 7.870 soldados, el número de monturas creció de 1.082 a 1.839; se fabricaron más de 700.000 balas y 200.000 cartuchos, también 6.000 vestuarios, 5.000 juegos de herraduras (Albi, 2009, 267). En enero de 1821 los jefes militares, entre ellos Canterac, obligaron al virrey a que abdicara, reprochándole pasividad e inca- 
pacidad a detener la avanzada patriota reforzado por el desembarco de porteños y chilenos bajo el mando de San Martín. José Joaquín de la Pezuela retornó a España; luego Canterac presenció las negociaciones de Punchauca entre el virrey La Serna y San Martín, paso hacia una eventual regencia. El proyecto conservador fracasó. En julio de 1821 el ejército realista evacuó Lima replegándose en la sierra, haciendo de Cusco la capital del virreinato, situada a más de 180 leguas, mientras que se proclamó la independencia en Lima. En dos operativos inesperados Canterac intentó recuperar Lima en 1821 y en 1824 .

La primera expedición en agosto de 1821 con 2.400 soldados y 900 caballos fue descrita por el general en el parte oficial al virrey después de fracasar. El informe oficial de siete páginas ${ }^{12}$ es informativo aunque a veces lírico, con estilo florido muy distinto del recato de las cartas íntimas ya mencionadas en este trabajo. Escrupulosamente apunta los lugares y horarios. A los enemigos los define como "vandidos [sic], negros de todas las haciendas a quienes el Jeneral San Martín había armado»; esa "chusma» da muestras de cobardía cuando se enfrenta a las tropas nacionales, que reúnen a «soldados valientes» que demuestran un «ardor increíble», «sufrimiento y constancia en dificultades insuperables» $\mathrm{y}$ "no necesitan más parapetos que sus pechos» a diferencia de la infantería enemiga parapetada detrás de tres órdenes de tapias». Canterac insiste también en los cerros escabrosos, la falta de agua en los largos tramos por la costa. Se exaspera al recordar los días anteriores:

A la vista de [el Callao] recordaron estos infames los vicios en que habían vivido en él encenegados y que tantos males ha traído a la disciplina de este ejército [...] se abandonaron al más detestable crimen, olvidando el honor y constancia que siempre ha distinguido a los soldados espańoles.

Más de 30 oficiales y 500 reclutas desertaron; los realistas se vieron obligados a replegarse hacia la sierra central, pasando por Puruchuco y Huamantanga. En Puruchuco «los bizarros granaderos» y su «valioso capitán» fueron cercados por 400 montoneros a los que

12 Colección de los principales partes y anuncios relativos a la campaña del Perú desde 29 de enero de 1821 en que tomó el mando el señor La Serna hasta el fin de marzo de 1824 dispuesta por el Estado Mayor Jeneral del Ejército https://archive.org/stream/colecciondelospr00tern\#page/n7/ mode/2up se enfrentaron en un cuerpo a cuerpo, a bayonetazos y cuchilladas. Desde la mirada patriota, la pasividad de San Martín, quien disponía de medios para deshacer la expedición de Canterac fue un argumento para cuestionar la actuación del Protector, acusado de complicidad con los realistas.

Las cartas que San Martín le dirigió a Canterac a finales de 1821 y que fueron estudiadas por Lorenzo Silva Ortiz (1998) son reveladoras de la insistencia de San Martín por negociar a favor de un gobierno monárquico afín a la situación de México, también ponen de manifiesto la negativa de Canterac por sustituirse a La Serna en esa reiterada propuesta de negociaciones secretas.

El 5 de febrero de 1822, Canterac difunde desde el cuartel general de Huancayo un bando sumamente amenazador hacia los habitantes de Lima: «Si ciegos a vuestro interés favorecéis los designios de los revoltosos, tened a la vista el castigo que acaban de sufrir los habitadores del Huayhuay Chacapalpa y otros, cuyos pueblos por su obcecación han sido entregados a las llamas $^{13}$ ".

La segunda acción de Canterac es más exitosa y tiene lugar el 7 de abril de 1822. Se trata de la batalla de Ica que resulta segundaria al final de la guerra pero que valora con creces el general en momentos en que informa al Estado Mayor de su éxito ${ }^{14}$. Compara esa batalla con la guerra europea en la que participó entre 1808 y $1814:$

En Europa centenares de millares de hombres fijan en una acción la decisión de una campaña, y en América el corto número de cinco o seis mil combatientes entre ambas partes deciden la suerte de un Imperio.

El balance es preciso como siempre: 1.000 soldados y 50 oficiales prisioneros, 4 piezas de artillería, 2.000 fusiles, 2 banderas y una imprenta de campaña. La batalla de Ica tuvo lugar de noche, en momentos en que los soldados patriotas intentaban evacuar la ciudad: el orden y el entusiasmo de los nacionales posibilitaron el paso inesperado de los Andes y llegar de improviso a la costa. Claro que el punto de vista

13 CDIP, Documentación oficial española, tomo XXII, vol. 3; Gobierno virreinal del Cuzco, Lima, 1973, 143.

14 "Batalla de Ica ", 7 avril 1822, ibid, 7-10. https://archive.org/stream/ colecciondelospr00tern\#page/n7/mode/2up 
patriota es diferente: si los generales criollos considerados como culpables de la derrota son condenados y separados de sus cuerpos por unos meses, parte de los prisioneros fueron ejecutados por los nacionales obedeciendo la orden despiadada de Canterac.

Éste tuvo un segundo éxito en enero de 1823: fueron las batallas de Torata y Moquegua (1.000 prisioneros entre ellos 69 oficiales, 3.000 fusiles, 3 piezas de artillería), por las que ironiza sobre el ejército «libertador» del sur derrotado. A partir de entonces, desde esa visión colonialista que tiene Canterac, lo que falta es reconquistar Lima.

Con un ejército de 9.000 soldados, entre los cuales muchos prisioneros, Canterac retoma Lima el 18 de junio de 1823. En esa ocasión el capitán Prescott tiene una entrevista el 23 de junio con el alto oficial hispano-francés y lo retrata luego otro testigo inglés, Robert Proctor: «Se me ha dicho que personalmente no es valiente; cierto que no es querido por los soldados como Valdez, más intrépido y audaz en el mando. Es de baja estatura, rubio, con finas barbas ensortijadas ${ }^{15}$ ». Al cabo de un mes debe evacuar la capital después de imponer un cupo e intentar recuperar la platería virreinal para acuñar moneda. En ese repliegue ordena llevar vestuarios para 10.000 soldados y 800 fusiles; los realistas vuelven al punto de partida, cruzando los Andes a marchas forzadas hasta el Cusco, seguidos por 3.000 civiles atemorizados por el regreso de los patriotas (Albi, 2009, p. 460).

Los escritos de Canterac desvían la interpretación de aquellos ańos de conflicto colonial. Otra imagen de la guerra, del todo opuesta, está en los mensajes de los guerrilleros sobre el actuar de las tropas «nacionales». Todos los movimientos son vigilados discreta y constantemente, de manera que el discurso de la represión ausente de los informes oficiales dedicados a celebrar los éxitos y matizar los fracasos, trasciende en los testimonios precisos de los montoneros, hombres de palabra más que de escritura.

Así informan sobre la orden de detener las familias de los hombres que sortean el alistamiento, también incendiar las casas hasta arrasarlas, el ganado es requisado sin cuidar la supervivencia de los pobladores:

15 CDIP, Relaciones de viajeros, v. 2, Proctor «El Perú entre 1823 y 1824", 213-214
El treinta de Agosto llegaron los enemigos que fueron al Serro, trajeron como cuarenta mil cabezas de ganado lanudo, como quinientos a seiscientos vacuno, algunos prisioneros de la gente paisana; dicen aber entrado hasta Guamantaga, y an traido otras muchas cosas que an robado.

En toda la Provincia están acopiando con mucha fuerza.

Montoneras con orden de Canterac, que en su dicha orden manda que si alguna persona se retirase de su casa sean apresados sus familias que quedasen en dicha su casa y que sean quemadas y arruinadas hasta el último, con esta orden la mayor parte se ban obligando a la fuerza (Carta a Tadeo Téllez de Antonio Aliaga, 12 de agosto de 1822, CDIP, t. V, vol. 1, 433)

Otra carta del 6 de agosto de 1822, dirigida al teniente 50 y firmada número 30, avisa sobre los uniformes de los realistas y expone el mismo ensañamiento propio del engranaje en la guerra:

\begin{abstract}
Ahora están con mas fuerzas en toda la Provincia para que harmen sus Montoneras en cada Pueblo, que nos hamenasan al que huvediciese que quieren dejarle en cenisa todas sus cosas (que ha dado ese vando Canterac). (ibid., 436)
\end{abstract}

El hispano-francés aparece como responsable del régimen de terror, cubriendo la tortura, las ejecuciones en masa de prisioneros comprometidos o sin compromiso con los patriotas, mujeres y niños, toda clase de represalias y maniobras para atemorizar a la población. Cuando se investiga la historia personal de Canterac, parece indudable que esa insensibilidad nació en la experiencia precoz de la violencia política impulsada por la Revolución francesa y que alcanzó hasta los poblados más apartados del sur de Francia. Las campañas de terror en los Andes fueron réplicas de ese cataclismo decretado por los revolucionarios franceses arrasando todas las huellas de la antigua nobleza para empezar una nueva era.

La situación entre los dos bandos evoluciona muy poco hasta 1824 , pese a la llegada de las tropas y los Libertadores procedentes de la Gran Colombia. Los refuerzos independientes reciben vestuarios y pertrechos gracias a la labor de los cajamarquinos. La situación en Espańa, el restablecimiento del absolutismo fernandino después del trienio liberal (18201823) tiene repercusiones decisivas en el Alto Perú. 
El general Olañeta desconoce la autoridad del virrey La Serna a quien censura como liberal. Ese segundo pronunciamiento después de Aznapuquio debilita el ejército realista entre dos frentes, luchando con los patriotas y con las tropas rebeldes de Olañeta.

Como lo investigó Fernando Barrantes Rodríguez Larraín (2006), los franceses fueron numerosos en el bando patriota, uno de los oficiales napoleónicos llegados con San Martín, Brandsen hizo un pronunciamiento el $1^{\circ}$ de mayo de 1823 contra Canterac, por condenar a los extranjeros que no fueran ni españoles ni americanos y empuñaran armas contra el ejército realista.

Más allá del discurso nacionalista y de reivindicación patriótica que construyen y legitimizan la historia del Perú republicano, las batallas de Junín y Ayacucho a la vez son hazañas de los patriotas y errores tácticos de la defensa realista. Como comandante en jefe, Canterac fue responsable de la derrota de Junín que se libró en presencia de Bolívar el 6 de agosto de 1824, y como jefe de Estado Mayor, sin quererlo contribuyó en el fracaso de Ayacucho en que el virrey La Serna fue hecho prisionero. Canterac firmó las capitulaciones condenándose a ser un "Ayacucho", nombre infamante para los espańoles, como autor de la vergonzosa rendición después de tres siglos de dominio imperial.

La batalla de Junín se caracterizó por el enfrentamiento de dos caballerías (1.300 realistas, 900 patriotas). Canterac decidió desplegar los jinetes en línea, en un combate al sable y a la lanza. Bajando por un terreno pantanoso, ordenó perseguir al enemigo derrotado. Los realistas lanzados a toda velocidad demasiado temprano, dispersos en el desfiladero, debilitados por el manejo de las armas desde sus monturas, sin el tiempo de recuperar fuerzas por la distancia recorrida desde la víspera, cansados por el cuerpo a cuerpo sangriento, fueron sorprendidos por el contrataque de un escuadrón de húsares que causó la estampida de quienes resultaban vencedores unos minutos atrás. Canterac dio la orden de replegarse y nuevamente mandó recorrer cuarenta leguas en menos de tres días, sufriendo el acoso de la guerrilla patriota. En esas circunstancias desastrosas, no pudo evitar que desertaran 3.000 soldados.

El 9 de diciembre de 1824, en la pampa de Quinua se enfrentaron dos ejércitos numéricamente desiguales: 9.000 soldados del Rey y 5.700 soldados de la Patria. El virrey fue hecho prisionero por los montoneros patriotas, en ese momento según Miller "mientras los realistas iban trepando a las alturas, los patriotas desde el pie de ellas, los cazaban a su salvo y muchos de ellos se vieron rodar hasta que algún matorral o barranco los detenía» (Miller, 1910, 176)

$\mathrm{Al}$ comprobar la dispersión de las tropas realistas y las cumbres ya tomadas por las divisiones patriotas, Canterac negoció la rendición de las tropas españolas.

\section{Retorno a Espańa}

Los oficiales perdedores salieron del Perú y llegaron a Francia, al puerto de Burdeos en dos grupos, el virrey La Serna con Valdés, Ferraz y Maroto entre otros a bordo de la Ernestine ${ }^{16}$, mientras Canterac regresó a la tierra de sus antepasados a bordo del Ternaux, después de concertar una explicación provisoria de la derrota con los demás vencidos en Ayacucho.

William B. Stevenson, secretario de Cochrane, apuntó en su relato de viaje que Canterac escribió el 12 de diciembre de 1824, una carta ofreciendo sus servicios a Bolívar ${ }^{17}$. Si bien el tradicionista Ricardo Palma cita esa carta en la narración dedicada a la batalla de Ayacucho:

Excelentísimo señor Libertador don Simón Bolívar: Como amante de la gloria, aunque vencido, no puedo menos que felicitar a vuecencia por haber terminado su empresa, en el Perú, con la jornada de Ayacucho. Con este motivo tiene el honor de ofrecerse a sus órdenes y saludarle, en nombre de los generales españoles, su afectísimo y obsecuente servidor que sus manos besa, José de Canterac. Guamanga, a 12 de diciembre de 1824

falta la respuesta de Bolívar a Canterac que encontré. Bolívar le agradece los cumplidos por la victoria y contesta con otros tantos elogios a la vez que envía los pasaportes para salir del país. Todo lo cual matiza la acusación de falsedad y corresponde a la natural cortesía:

16 Alberto Wagner de Reyna, «Ocho años de La Serna en el Perú (De La Venganza a la Ernestine», Quinto Centenario, 8, Madrid, 1985, 37-59.

17 W.B. Stevenson, Relation historique et descriptive d'un séjour de vingt ans dans l'Amérique du Sud, Paris, Kilian, 1826, v. III, 380. La carta fue incluida en la tradición de Ricardo Palma «Pan, queso y raspadura» (véase la versión digitalizada de la tradición). 
la conducta de Uds. en el Perú como militares merece el aplauso de los mismos contrarios. Es una especie de prodigio que Uds. han hecho en este país. Ustedes solos han retardado la emancipación del Nuevo Mundo, dictada por la naturaleza y por los destinos ${ }^{18}$.

Las memorias de Miller, escritas en $1829^{19}$ son sumamente instructivas acerca de Canterac y del todo opuestas a la más mínima sospecha de traición del alto oficial. Miller traza la biografía de Canterac desde la emigración a España, la carrera militar iniciada muy precozmente y en la que «se señaló por su inteligencia y valor» (Miller, 185). Continúan los elogios: "Canterac es organizador, un excelente táctico y tiene muy buenas maneras» (Ibid.), con lo que Canterac se diferencia del general Valdés ${ }^{20}$, "violento, precipitado, despótico y descortés [...] temido de los oficiales, pero idolatrado de la tropa» (Miller, 187).

Desde Río de Janeiro, el $1^{\circ}$ de abril de 1825 , Canterac solicita ser recibido por el Rey y cuenta los últimos meses de la guerra: «Estábamos siempre rodeados de puñales que agitaban manos invisibles, que cada momento amenazaban [...] varias revoluciones promovidas por jefes y oficiales que parecían de nuestra confianza» sin olvidar las penurias por las que pasaban los soldados rasos: «el vestuario del soldado se buscaba y tejía por la misma tropa del modo más económico, y el alimento a pesar de parco tenía que buscarse a grandes distancias».

Al desembarcar en Francia, Canterac tiene dos prioridades: presentarse ante el Rey para explicar lo sucedido y recibir la indemnización prevista desde la Restauración francesa para los emigrados según explica en carta del 20 de junio:

18 Oficio del libertador para el teniente general José de Canterac, fechado en Lima el mes de diciembre de 1824. Documento 10040 en http://www.archivodellibertador.gob.ve/escritos/buscador/spip. php?article9900

19 La traducción de Miller es del general Torrijos y la edición de 1910 (Madrid, Victoriano Suarez). Edición electrónica del Ministerio de Cultura

http://bvpb.mcu.es/es/consulta/resultados_navegacion.cmd?busq_ autoridadesbib=BVPB20070032633. Incluye entre los anexos oficios fingidos con falsas noticias y cartas interceptadas por Miller para engañar a los realistas.

20 Valdés fue edecán de Ballesteros, quien se opuso al ascenso de Canterac en 1816
Dé cuenta que a su vuelta a Francia se halla con el caso de que toda su fortuna consiste en la indemnización acordada por aquel Gobierno a los emigrados o sus herederos que para una disposición de la ley, deve darse todos los pasos para el recobro de sus derechos y además por hallarse también extremadamente su salud, retardan su entrada en España, aunque procuraría ser cuanto antes.

La administración francesa deseaba informarse lo antes posible sobre los derrotados. Un informe fue enviado desde la prefectura de Gironda a París, con las noticias comunicadas por el vicecónsul interino de España quien manifestó celo y «afecto a los Borbones de Francia y España» en esa pesquisa ${ }^{21}$. Resultaba sumamente interesante por mostrar el amplio abanico de testimonios e interpretaciones. Quien acompañaba al secretario del prefecto y hacía las veces de traductor era nada menos que el vicecónsul español, representante de la Corona. Exculpa a La Serna, como víctima de los liberales entre los cuales ubica a Valdés:

En circunstancias en que creyó útil manifestar su autoridad, lo detuvo el general Valdés, diciéndole: «No se le prestará atención... Usted es el virrey, es cierto, pero tiene que saber que si somos capaces de hacer virreyes, también sabemos derrocarlos». Obligado a obedecer los caprichos de sus subalternos, por tanto Laserna sólo fue un instrumento que aquellos usaron a su antojo. Por lo demás, es un hombre bueno, sacrificado al Rey; pero no tiene ni los medios ni el genio que conviniera al jefe de una colonia alejada.

Valdés es el genio del mal en esa lectura de la historia del Perú por el cónsul español:

En circunstancias en que creyó útil manifestar su autoridad [La Serna], lo detuvo el general Valdés, diciéndole: «No se le prestará atención... Usted es el virrey, es cierto, pero tiene que saber que si somos capaces de hacer virreyes, también sabemos derrocarlos». Obligado a obedecer los caprichos de sus subalternos, por tanto Laserna sólo fue un instrumento que aquellos usaron a su antojo. Por lo demás, es un hombre bueno, sacrificado al Rey; pero no tiene ni los medios ni el genio que conviniera al jefe de una colonia alejada

21 Ascensión Martínez Riaza me proporcionó la copia de ese informe manuscrito de 9 folios, dirigido al ministro de Asuntos Exteriores francés. 
Los derrotados hubieran cantado cantos sediciosos al abandonar el Perú, con excepción del general Maroto quien retornaba a Espańa con su mujer y los cinco hijos de la pareja y terminó por amenazar de muerte a los pasajeros para que se quedaran callados:

Durante la travesía los españoles a bordo de la Ernestine hasta Río de Janeiro no dejaron de cantar contra el Rey de España, los Borbones y el gobierno francés, la canción más ruin, en lo que tomaron parte el capitán, el cirujano de a bordo y varios otros individuos de la tripulación. Varias veces el general Maroto suplicó al virrey que interpusiera su autoridad para acallar esos cantos sediciosos; no obtuvo nada de éste.

A eso se suma el relato de la batalla de Ayacucho, con una victoria debida a traiciones internas en el ejército del Rey, pues se habrían encendido fogatas convirtiendo a los soldados en fáciles blancos para los patriotas:

A las once de la noche, en medio de las tinieblas más espesas, los generales dieron la orden de encender unas fogatas delante del campamento. Ejecutada la orden, el enemigo se dio prisa en disparar a las tropas realistas y las fogatas sólo fueron apagadas cuando muchos soldados y dos altos superiores resultaron muertos.

Por último, el informante de Burdeos plantea que después de echarle la culpa de la derrota a Canterac, los retornados llegaron a un acuerdo sobre la versión oficial que iban a presentar:

los jefes del ejército no dejaron de echarle la culpa al general Canterac, pero llegado éste a Río, antes de la salida de la Ernestine, cambiaron de lenguaje y acordaron con él el relato que habían de dar para justificarse. Es de notar que Canterac, después de haber capitulado, no quiso viajar con el virrey, que se quedó con los independientes y fue con ellos hasta Cusco.

Con esa indirecta recae la suspicacia sobre Canterac. Y el diplomático español satisface plenamente a las autoridades francesas y españolas que solicitaron sus servicios al agregar insistiendo en su papel de testigo fehaciente:
Los republicanos con los que conversé, no creen que el Perú siempre se mantenga fuera de España. Dan como razón que la mayor parte de los habitantes se inclina por la madre-patria, que las tropas Realistas aún ascienden a 7 o 8.000 hombres, descontando a los que están en el Callao y cuyo número se calcula en unos 3.000 hombres. Con unos jefes sacrificados, según dicen, pronto a los independientes se les expulsará del Perú.

Cuestionado por un artículo publicado en el diario Memorial Bordelais ${ }^{22}$, el 8 de julio de 1825 ( ${ }^{\circ}$ 4637), José de Canterac contesta con una carta abierta redactada en francés, en ese mismo periódico, el 21 de julio ( ${ }^{\circ}$ 4650). Explica su ausencia de Burdeos en los días anteriores por problemas de salud y los intentos de recuperar la herencia familiar. Anuncia la decisión de ir a Madrid para dar cuenta de su actuación y que se tomara en cuenta el impacto de la rebelión de Olañeta en el debilitamiento de las tropas y la derrota. Curiosamente la noticia de la muerte de Olañeta, ocurrida en abril de 1825 , se da a conocer en el Memorial Bordelais, sólo al día siguiente de las justificaciones de Canterac ( $\left.n^{\circ} 4651\right)$. La Francia de 1825, gobernada por el rey Carlos X, políticamente se identifica con el absolutismo de Fernando VII.

El dossier del Archivo Militar de Segovia permite seguir los pasos del general derrotado por España. Pese a las órdenes de impedirle acercarse a la Corte por ser «agente principal de la capitulación poco decorosa a las Armas según escribe el marqués de Zambrano (carta del 8 de agosto), Canterac ya está en Alcobendas a finales de julio y denuncia «la perversidad de [sus] enemigos ocultos»; en vano solicita ser destinado a las provincias vascongadas por «aquel temperamento más análogo a su salud que el de Castilla la Vieja» y "para el arreglo de sus intereses» (carta del 3 de agosto de 1825). Es asignado al cuartel de Burgos a mediados de agosto. Al ańo siguiente, la vida de Canterac toma otro rumbo; es autorizado por el Consejo de Guerra a casarse con la hija del intendente general de Valladolid, Manuela Domínguez nacida en Ceuta, de dieciocho ańos, con quien tendrá cinco hijos ${ }^{23}$. De esa manera, la situación econó-

22 El diario Le Memorial Bordelais está conservado en las colecciones patrimoniales de la Biblioteca Municipal de Burdeos.

23 El padre del intendente Domínguez nació en Bayona y el abuelo materno fue teniente del Rey, entre otras informaciones entrega das para el casamiento con José Canterac. 
mica del francés queda definitivamente solucionada. Acuartelado en Valladolid, José Canterac no recibe destino militar a su medida hasta 1833 , cuando es nombrado comandante general de Gibraltar ${ }^{24}$, y luego en 1835 capitán general de Castilla. Muere en el intento de sofocar un motín militar en Madrid en enero de ese mismo año.

Después de su muerte, la viuda recibirá el título de condesa de Canterac y no escatimará esfuerzos para recibir una pensión no sólo de la Corona sino también llegando a reclamar en carta del 29 de septiembre de $1843,40.179$ pesos del gobierno peruano con el argumento de imitar a otros militares españoles en semejante petitoria.

La guerra en la América meridional vista por esa figura máxima que fue José de Canterac se emparenta con las guerras europeas como él mismo lo observó, tanto por el espacio continental en conflicto, las distancias recorridas de un frente a otro, y la presencia de oficiales formados en la guerra de independencia de España ${ }^{25}$ y que siguen la carrera militar ya en el bando realista ya entre los insurgentes, siendo el ejemplo más relevante San Martín. Sin embargo, el armamento y las fuerzas desplegadas fueron más de diez veces inferiores. En los Andes, como los demás altos oficiales llegados de la península, Canterac se vio sumido en una realidad incomprensible, comandando tropas en las que los peninsulares eran poco numerosos, los soldados hablaban quechua -idioma incomprensible del general nacido en Europa- les prisioneros se veían integrados a la fuerza y requerían una vigilancia constante. Les refuerzos esperados no llegaron a causa del trienio liberal y de la guerra interna en España; faltaron en el momento de la secesión de Olañeta en el Alto Perú.

Ningún otro francés desempeñó un papel tan notable en el ejército colonial. Un buen número de ofi-

24 El puesto de Gibraltar conllevaba un riesgo político pues en la primera guerra carlista contra la regenta María Cristina quien permitió la reintegración de Canterac, radicaban en el peñón los exiliados liberales. Además de mantener el orden público, Canterac mandó remodelar la ciudad de Algeciras dotándola de un jardín público a la francesa.

25 En la guerra de independencia española, la deportación de soldados y oficiales a Francia representó entre 50.000 y 60.000 hombres. Véase Jean-René Aymes: La déportation sous le premier empire des Espagnols en France (188-1814), Paris, Publications de la Sorbonne, 1983, 169-171. ciales del ejército de Napoleón emigraron a América en 1815 y se incorporaron en las filas patriotas, reverenciando al emperador y a la par el ideal igualitario de la Revolución. Los relatos de viajes publicados después de 1821 suelen recordar a esos oficiales que forman la élite militar de las nuevas repúblicas junto a capitanes de otras nacionalidades.

Cuando, a los diez años del regreso a Espańa, Canterac solicita nacionalizarse y se enfrenta a una oposición difuminada, él mismo escribe un discurso para defenderse. La nacionalidad no le será concedida. El alegato pro domo merece ser recordado: se trata de una carta pública que homenajea tardíamente a Napoleón contra quien Canterac peleó durante los siete ańos de la guerra de independencia: «He tenido la honra de que se haya dicho, que la expedición que mandé en el año 1821 sobre el Callao, haría honor al primer capitán de nuestro siglo ${ }^{26}$ ".
26 En esa carta redactada en Algeciras, el 15 de octubre de 1834 para solicitar la "naturalización" Canterac pasa lista de los combates en que participó en Espańa e insiste en su fidelidad a la Corona española. La carta fue publicada por Santos Rodrigo en «Canterac: apuntes biográficos», Revista de Historia Militar, 1975, n 39; 76-98. 


\section{Anexo}

Prefectura de Gironda /Gabinete ${ }^{27}$

folios numerados 269-273

Burdeos 9 de junio de 1825/14 de junio

Informe

Monseñor

$\mathrm{Al}$ margen izquierdo figuran anotaciones de un lector no identificado que resume los párrafos.

Las informaciones que recogí junto a los principales oficiales del antiguo ejército Real del Perú y también de algunos empleados civiles que llegaron con ellos me permiten hacerle un informe sobre los sucesos de la América del Sur y sobre la situación de esa comarca. Voy a empezar dándole a conocer al teniente general Laserna y los distintos individuos que lo acompańaron.

Su Excelencia no ignora que en 1820, Laserna sólo fue enviado al mando de las tropas y al virreinato a causa de la defección de los generales españoles que quisieron librarse de la autoridad del virrey Pezuela, varón íntegro y enteramente fiel al Rey. Desde entonces, el general Laserna se vio en la posición más falaz, y cuando quiso actuar por los intereses de Su Majestad, casi siempre se enfrentó con obstáculos insuperables. En circunstancias en que creyó útil manifestar su autoridad, lo detuvo el general Valdés, diciéndole: «No se le prestará atención... Usted es el virrey, es cierto, pero tiene que saber que si somos capaces de hacer virreyes, también sabemos derrocarlos». Obligado a obedecer los caprichos de sus subalternos, por tanto Laserna sólo fue un instrumento que aquellos usaron a su antojo. Por lo demás, es un hombre bueno, sacrificado al Rey; pero no tiene ni los medios ni el genio que conviniera al jefe de una colonia alejada y cuya situación desde hacía años resultaba insegura y a menudo crítica. Aunque realista, se cree a Laserna atraído por el gobierno constitucional.

El mariscal de campo Valdés reveló su genio por las palabras que acabo de citar. Es un hombre vicioso y un partidario acérrimo de la independencia; sólo combatió con los realistas para asegurarse mejor el enriquecerse a expensas de todos aquellos a los que pudo sacrificar. De él se refieren rasgos que anuncian un alma negra y cruel. En campaña, a la cabeza de su división, se asegura que cobró una contribución enorme a las ciudades, villas y pueblos por donde estuvo y que no descartó ni la prisión ni los azotes para hacerse pagar: se llega a decir que mandó fusilar a funcionarios que

27 Traducción de Isabelle Tauzin. resistían a sus órdenes. Enemigo acérrimo de Canterac, el general Valdés no vio en él sino a un temible antagonista que contrariaba sus planes. Esa rivalidad fue la que impidió en 1820 que se proclamara la independencia del Perú que Canterac había estipulado con el general San Martín. Enterado de esa circunstancia, Valdés no descuidó nada para que no hubiera una continuación, no tanto por amor al rey como por despecho de haber sido informado. Desde aquella época se había allegado a Canterac; hasta se cree que existe entre ambos un tratado secreto y se atribuye a esos dos hombres con mucha verosimilitud los éxitos de Bolívar.

El mariscal de campo Villalobos, satélite de Valdés, constitucional independiente como él, siempre fue el agente más activo del dominador del Perú. A ese general hoy le afecta demencia; aquí ésta según me aseguraron la única y verdadera causa: Villalobos quien, mejor que ningún otro, se conoce a fondo todas las intrigas de Valdés y demás, hizo unas confidencias al marcharse del Perú, al mariscal de campo, Maroto, hombre profundamente convencido a favor de la monarquía. Valdés y los suyos se enteraron y se lo reprocharon y le amenazaron tanto que enloqueció.

El mariscal de campo es un excelente realista, sacrificado a su Rey, honesto, con genio fuerte y que por eso siempre fue apartado por Valdés y demás. Un solo hecho bastará para dar una idea del general Maroto. Durante la travesía los espańoles a bordo de la Ernestine hasta Río de Janeiro no dejaron de cantar contra el Rey de Espańa, los Borbones y el gobierno francés, la canción más ruin, en lo que tomaron parte el capitán, el cirujano de a bordo y varios otros individuos de la tripulación. Varias veces el general Maroto suplicó al virrey que interpusiera su autoridad para acallar esos cantos sediciosos; no obtuvo nada de éste; algunos de los más rabiosos quedaron en Río de Janeiro, creía que semejantes cantos ya no llegarían a sus oídos; pero no sucedió así. Un día en que estaba en el camarote mientras cantaban, envió al subteniente Joseph Roda para acallar a los cantantes; éste fue despedido con menosprecio. Maroto subió entonces a cubierta y en presencia del capitán de navío, quien profesa los peores principios (lo señalé al procurador del Rey) acalló a esos energúmenos, diciéndoles que le reventaría los sesos al primero que siguiera atreviéndose a decir palabras sediciosas. Desde entonces terminaron los cantos sediciosos. La firmeza del general es tanto más meritoria que lo acompañaban su mujer y cinco hijos.

El brigadier Landazuri oriundo del Perú, siempre fue el confidente de Valdés, cuyos principios comparte.

El brigadier Valentín Ferraz es aún peor. 
El coronel Santa Cruz, secretario del virrey, tal vez sea más peligroso que el anterior, por el fanatismo de sus opiniones liberales.

El coronel Ruperto Delgado y el teniente coronel Vigil son hombres nulos.

Los coroneles Bravo y Francesco Arce son militares valientes, sacrificados al Rey.

El tesorero del Perú Sanchez Chabez es un hombre de bien en todos los aspectos; en todas las circunstancias dio las pruebas de la mayor abnegación, razón por la cual el dominador del Perú siempre lo mantuvo apartado.

El inquisidor Enselmo de la Canal es un hombre nulo.

El administrador de la aduana de Arequipa, Narciso de Benavidez se doblega en cualquier circunstancia.

El capitán Siol y Antonio Morati y el teniente Salvador Armar son realistas.

El cirujano Minier o Miner, quien hoy cuida al virrey, el teniente Philippe Mechandre y el subteniente francés Quiroga son hombres muy peligrosos. Ellos eran los más empeñados en pronunciar palabras contrarias al Rey y cantar canciones sediciosas. Una de aquellas canciones terminaba con el estribillo: mueran los Borbones.

Con un ejército en el que la mayoría de los jefes eran liberales y acérrimos contra el Rey, era difícil que el Perú siguiera conservado por España.

Si se cree en el virrey, el general Valdés y demás, ellos son los causantes que explican la derrota del Ejército Real.

Desde hacía cuatro años, ninguna fuerza de la metrópoli fue enviada al Perú. Reducido a 800 hombres regulares, el virrey reunía a indígenas lo más que podía, entre los cuales repartía viejas bandas para contenerlos; pero sus esfuerzos no podían hacer unas tropas fieles; batallones enteros pasaban al enemigo.

En mayo de 1824, el ejército Real esperaba refuerzos y mantenía observado el ejército enemigo, acuartelado en las inmediaciones de Trujillo: en cuanto a Bolívar, esperaba tropas de Colombia para actuar. En ese momento había de enviarse un destacamento con el general Valdés contra el general Olañeta, quien desconocía la autoridad del virrey y quería ser el dueńo absoluto del poder, de la Paz, Potozy etc. la más rica región del Perú, de la que era gobernador.

El ejército realista, demasiado débil para iniciar las hostilidades contra los generales de Bolívar, se mantenía en la defensiva; pero habiendo recibido los refuerzos desde finales de junio, éste empujó a Canterac hasta Cusco. Aquí, Valdés quien había reducido a Olańeta, o mejor dicho, había tratado con él, alcanzó las tropas realistas y el virrey tomó el mando del ejército. Este ejército, al salir de Cusco, contaba con 9.000 soldados de infantería y 1.000 de caballería pero, exceptuando 800 hombres, eran indígenas, entre los cuales más de 3.000 desertaron antes del asunto decisivo. Sin embargo, el virrey atacó a los independientes, los venció en varias ocasiones y los expulsó hasta la posición de Ayacucho donde se inició la batalla. Las tropas realistas del país se desbandaron pronto, pasaron al bando enemigo, un capitán y un teniente que quisieron impedirlo, fueron matados por los desgraciados; el virrey fue herido, hecho prisionero y los generales Canterac y Valdés después de ver segados en torno suyo a los que les seguían fieles, se retiraron.

De ahí el tratado de Canterac, con los generales de Bolívar, Sucre y Lamar.

El general Laserna considera que el ejército de éstos contaba con 6.000 o 7.000 hombres, buenas tropas en momentos del enfrentamiento. De los controles [?:?] hallados en las fuerzas del general Sucre, caído en poder de los Realistas unos días antes ascendían el total del ejército a 12 o 14.000 hombres.

El virrey denuncia a Olañeta como la principal causa de sus reveses y lo acusa de querer ser independiente de cualquier autoridad en la provincia de la que es gobernador, y ocultar sus ambiciones bajo el ropaje del Realismo. Olañeta se separó de él, con el pretexto de que no quería reconocer el gobierno de las Cortes, y cuando la noticia del derrocamiento de ese gobierno y la confirmación de la autoridad del virrey por SM le hubieron llegado (en octubre de 1824) no dejó de persistir en la rebelión.

Por fin, el general Laserna no cree que el general Olañeta pueda resistir largo tiempo; es — dice— un soldado que ha ascendido, valiente, pero sin medios cuyos recursos pronto estarán agotados; no tiene más de 2.000 soldados consigo. Para reconquistar el Perú, agrega, se necesitaría un ejército de 10.000 soldados mandados por un jefe y generales con experiencia y que conocieran los lugares, apoyada por una escuadra de dos naves de línea, dos o tres fragatas y unos cuantos barcos pequeńos, y reforzado cada año por al menos 2 o 3.000 hombres de la metrópoli.

Los oficiales y empleados realistas distan mucho de compartir la opinión del virrey acerca de Olañeta y atribuyen el éxito de Bolívar a otras causas que las que acabo de referir. Aquí tiene lo que he aprendido con ellos.

Olañeta sólo se separó del virrey porque conocía sus debilidades y las metas pérfidas de sus oficiales. Pese a todo, no dejó de enviar a Cusco, sede del gobierno del virrey, todas las contribuciones recaudadas en las provincias bajo sus órdenes; e informado que Bolívar, en una de sus proclamas lo había citado como partidario de la independencia, le escri- 
bió al virrey para ofrecérsele con su División como auxiliar. Ese ofrecimiento permaneció sin respuesta.

La pérdida del Perú se explica por dos causas principales. Una fue la estancia demasiado larga en Lima del ejército Realista; en 1824, después de la rendición de la fortaleza del Callao entonces en manos de los independientes. Si Canterac y los demás generales en lugar de entregarse a todo tipo de exceso y desenfreno, se hubiesen ocupado a perseguir a Bolívar (en mayo), le hubieran asestado el último golpe a la Independencia de esa parte de América. Otra causa fue el empeńo de los jefes por negarse siempre a encabezar sus ejércitos con los 1.500 soldados y oficiales del batallón de Buenos Aires que habían abandonado a Bolívar para formar parte de las tropas Realistas. Al contrario, esos militares fueron enviados a las costas meridionales a más de 200 leguas del teatro de la guerra. A esas dos causas cabe sumar dos sucesos: $1^{\circ}$ la situación [į?] de la batalla de Ayacucho, los Realistas estaban acampados al alcance de los fusiles de los independientes. A las once de la noche, en medio de las tinieblas más espesas, los generales dieron la orden de encender unas fogatas delante del campamento. Ejecutada la orden, el enemigo se dio prisa en disparar a las tropas realistas y las fogatas sólo fueron apagadas cuando muchos soldados y dos oficiales superiores resultaron muertos. $2^{\circ} \mathrm{El}$ general Valdés, quien mandaba una división, no tomó parte en la acción; sólo le había confiado dos batallones al brigadier Pacheco, quien peleó como valiente. $\mathrm{Al}$ ver el asunto perdido, Valdés dejó su división, la cual con excepción de los dos batallones que acabo de mencionar, no había disparado ni una vez y se disponía a reunirse con el general Sucre cuando su edecán corrió hacia él y le preguntó adónde iba: - A capitular, contestó Valdés — infame! — repuso Pacheco- Vuelva a encabezar su división o le cruzo el cuerpo con mi espada. Obedeció Valdés; pero Canterac pronto llegó para capitular.

El brigadier Pacheco está a bordo del navío Le Ternaux que se espera en Burdeos de un día para otro; podría proporcionar muchas informaciones. Ese alto oficial es Realista; y como se conocía todos los manejos de Valdés y demás, ese general lo tomó como edecán y lo llenó de favores, pensándose así cerrarle la boca.

Durante el viaje de L'Ernestine de Quilca a Río de Janeiro, los jefes del ejército no dejaron de echarle la culpa al general Canterac, pero llegado éste a Río, antes de la sali- da de la Ernestine, cambiaron de lenguaje y acordaron con él el relato que habían de dar para justificarse. Es de notar que Canterac, después de haber capitulado, no quiso viajar con el virrey, que se quedó con los independientes y fue con ellos hasta Cusco.

Los republicanos con los que conversé, no creen que el Perú siempre se mantenga fuera de Espańa. Dan como razón que la mayor parte de los habitantes se inclina por la madre-patria, que las tropas Realistas aún ascienden a 7 u 8.000 hombres, descontando a los que están en El Callao y cuyo número se calcula en unos 3.000 hombres. Con unos jefes sacrificados, según dicen, pronto a los independientes se les expulsará del Perú. En cuanto a Olañeta, podrá mantenerse largo tiempo, aun cuando Espańa no le enviara auxilios con tal que el gobernador de la provincia de Santa Cruz, oriundo del Perú, sacrificado al Rey, siga fiel a su juramento, lo cual parece probable. En el caso contrario, Olañeta se vería obligado a retirarse a la montańa, donde podría permanecer hasta que lleguen tropas de la Metrópoli.

Éstos, son, Excelencia, las informaciones que he podido recoger hasta ahora, y según las cuales no cabe duda de que el Perú fue entregado por aquellos que lo debían guardar. Sin embargo, como es de temer que la pasión no entre de alguna manera en los informes que me fueron dados, y que varios hombres entre aquellos a los que me dirigí, hayan tratado de valorarse a expensas de otros, sigo recogiendo información, cuyo resultado notificaré a Su Excelencia. La llegada del navío Le Ternaux, a bordo del que viajan Canterac, Pacheco y otros, me permitirá controlar las informaciones proporcionadas por el pasaje de L'Ernestine.

El Señor Esteban Ducot, vicecónsul interino a cargo del consulado de España, me ayudó mucho para obtener esas informaciones: en esas circunstancias nuevamente dio muestras de su sacrificio a los Borbones de Francia y Espańa, así como de su celo para cumplir con el servicio que se le confió.

Soy con profundo respeto,

Monseñor

de Su Excelencia

El muy humilde y muy obediente servidor.

Para el Prefecto de vacaciones, el secretario general delegado

Firma 


\section{Bibliografía}

\section{Fuentes primarias}

Archives Départementales du Lot-et-Garonne.

Legajo 2C570C Registro de casamientos desde 1 de septiembre de 1782 hasta prairial ańo XII ( $N^{\circ} 44 \mathrm{f} .16$ )

Legajo 1Q109

- Bienes de los emigrados (incluye la ordenanza sobre embargo de los bienes de los padres de emigrados, los decretos de la Convención -25/11/1792; 28/3/1793; 3/6/1793; 25/7/1793)

- Cartas desde 22 de brumario del año III, 13 de diciembre de 1808; 20 de mayo de 1809.

Archivo Militar General de Segovia:

Legajos C. 1004-0 y a la Caja 25-Exp. 3, carpetas 1, 2, 3, 4 microfilmadas

Archive Ministère des Affaires Etrangères

Informe sobre los acontecimientos de América y los principales oficiales del ejército español llegados a Burdeos a bordo de la Ernestine (Rapport sur les événements de l'Amérique et sur les principaux officiers de l'armée espagnole arrivés à Bordeaux, à bord de l'Ernestine) 9 de junio de 1825 .

Colección Documental de la Independencia del Perú [CDIP], t. V, vol 1, tomo XXII, vol. 3 Lima, 1973

Colección de los principales partes y anuncios relativos a la campaña del Perú desde el 29 de enero de 1821 en que tomó el mando el señor La Serna hasta fin de marzo de 1824, dispuesta por el Estado mayor Jeneral del Ejército (digitalizado par John Carter Brown Library).

Cartas de Canterac y Lavalle recolectadas por Cristina Mazzeo (documentación privada)

\section{Fuentes secundarias}

Albi J., Banderas olvidadas. El ejército realista en América, Madrid, Cultura hispánica, 1990

Albi J. El último virrey, Madrid, Oller y Ramos, 2009.

Barrantes Rodríguez Larraín, Fernando, Los ciudadanos franceses y francesas en la República del Perú, Lima, Sociedad Francesa de Beneficiencia, 2006.

Contreras, R., Catálogo de la colección de Pablo Morillo, conde de Cartagena, t. II, Madrid, RAH, 1989. Digitalizado por la Real Academia de Historia.
Dunbar Temple, E (dir.), Colección Documental de la Independencia del Perú [CDIP]. La acción patriótica del Pueblo en la emancipación. Guerrillas y montoneras, Lima, 1971, t. V, vol. 1.

Labouche, C. (1924). "Un Agenais général en chef des armées espagnoles", Revue de l'Agenais, n 60, 444-451.

Martín-Lanuza Martínez, A. (2012). Diccionario Biográfico del Generalato Español - Reinados de Carlos IV y Fernando VII (1788-1833). Villanueva, Foro para el Estudio de la Historia Militar de España.

Martínez RiazA, A., "Todos eran realistas. Liberalismo y absolutismo en el gobierno del virreinato del Perú ", Izaskun Álvarez Cartero et Julio Sánchez Gómez (dir.), Visiones y revisiones de la independencia americana Realismo/pensamiento conservador, Salamanca, Universidad Salamanca, 2014, 121-143.

Mazzeo, C. (2009). «Los nudos de la desunión: conflictos $\mathrm{y}$ divergencias en la dirigencia del ejército realista durante la emancipación del Perú (1810-1824)», Revista de Indias, Madrid, vol. LXIX, n² 247, 105-136.

Miller, G. (1910 [1829]). Memorias del general Guillermo Miller al servicio del Perú. Madrid: Victoriano Suárez. Edición electrónica del Ministerio de Cultura http:// bvpb.mcu.es/es/consulta/resultados_navegacion. cmd?busq_autoridadesbib=BVPB20070032633.

NúÑez, E., Colección Documental de la Independencia del Perú [CDIP]. Relaciones de viajeros t. XXVII, vol. 2.

Roel Pineda, V. (1988). La independencia. Historia general del Perú. Lima: Gráfica Labor.

SAntos Rodrigo, E. de (1975). "Canterac: apuntes biográficos», Revista de Historia Militar, n³ 39, 76-98.

SAntos Rodrigo, E. de (1976). "Canterac: apuntes biográficos», Ejército, Revista de las armas y servicios, Madrid, $\mathrm{n}^{\circ} 439,13-18$.

Silva Ortiz, L. (1998). "La correspondencia entre San Martín y Canterac», en Luis Navarro García, José de San Martín en su tiempo, Sevilla, Universidad de Sevilla, 231-246.

Stevenson, W. B. (1826). Relation historique et descriptive d'un séjour de vingt ans dans l'Amérique du sud, Paris, Kilian, vol. III.

\section{Versión anterior de esta investigación}

José Canterac: de la historia local a la historia global, Fénix. Revista de la Biblioteca Nacional del Perú, 2017, n46, 13 págs. 